\title{
Failure of the Rational Expectation: Argumentation, Logic and Suggestions on Supply-Side Management
}

\author{
Kang Jia ${ }^{1}$, Qiaobin Feng ${ }^{2}$, Jingchun $\mathrm{Su}^{3}$ \\ ${ }^{1}$ Chinese Academy of Fiscal Science, the Ministry of Finance, P.R.C., Chief Economist in China Academy of \\ New Supply-side Economics, Beijing, China \\ ${ }^{2}$ Department of Macroeconomic Research of the Development Research Center of the State Council of the \\ People's Republic of China, Beijing, China \\ ${ }^{3}$ Chinese Academy of Fiscal Science, the Ministry of Finance, P.R.C., Beijing, China \\ Correspondence: Kang Jia, Chinese Academy of Fiscal Science, the Ministry of Finance, P.R.C., China \\ Academy of New Supply-side Economics, Beijing, 100142, China.
}

Received: November 21, 2019

Accepted: December 11, 2019 Online Published: December 13, 2019

doi:10.5539/ibr.v13n1p161

URL: https://doi.org/10.5539/ibr.v13n1p161

\begin{abstract}
Rational expectation is known as the sixth revolution in economics. Based on a brief review of rational expectation, this paper puts forward the proposition of failure of rational expectation. The so-called failure of rational expectation means that when the market entity predicts future events, it is impossible to form a completely accurate expectation and then adjust its actions accordingly due to incomplete information and other reasons. On the contrary, due to various irrational factors, the actions of the market entities based on individual ration sometimes may be mad and loss of control, producing devastating effects on the economic system. This paper expounds the concept and formation mechanism of the failure of rational expectation, and conducts a preliminary empirical analysis on this in combination with China's economic practice. On this basis, it proposes that rational supply management, which the government can play a role in, should be combined to correct the failure of rational expectation and realize the dynamic balance and stability of the economic system.
\end{abstract}

Keywords: failure of the rational expectation, supply management, lemon market, animal spirit

\section{Introduction}

The rational expectation is called the sixth revolution in economics, and its representative Robert E. Lucas was the winner of 1995 Nobel Prize in Economics. Since the 1970s, the rational expectation, as a major amendment to Keynesianism, has been regarded as one of the theoretical sources of long-term liberalism in major European and American countries. However, after the global financial crisis in 2008, the theory of free market, including rational expectation, is seriously questioned at the practical level. In economics, this indicates that the time window of some major theoretical innovations and breakthroughs has emerged. In China, on one hand, since the reform and opening up, the Chinese economy, which has obvious characteristics of government orientation, has experienced rapid growth for more than 30 years. The mainstream economic theory is weak in explanation this phenomenon. On the other hand, after years of stimulus policies, the Chinese economy has stepped into some kind of high growth trap, and the expectations of future optimism (including overly optimistic factors) are turning in the opposite direction. The international and domestic realities present signs and evidences of various challenges for rational expectations. We believe that the discussion from the rational expectation to the failure of rational expectation is the essential of economic theory innovation, and it is enlightening at the policy level. This paper attempts to make efforts in this regard.

\section{A Brief Review on Rational Expectations}

The rational expectations emerged in the early 1960s. At that time, the western countries had already felt the pressure of stagflation, and Keynesianism faced unprecedented martyrdom. In 1961, John F. Muth published an article entitled Theory of Rational Expectation and Price Fluctuation in the American Journal of Econometrics, which first proposed the concept of rational expectations. In the early 1970s, Robert E. Lucas in the University of Chicago, Thomas J. Sargent in Stanford University, and Robert Barro in Harvard University, etc. made a major development, forming the rational expectations and the school of rational expectations. 
The so-called rational expectation refers to people's well-founded predictions about future events, and the so-called basis, in addition to psychological intuition and experience, more importantly, refers to the support of economic theory. The assumptions are as follows. First, prices and wages are sufficiently flexible in market competition. Second, the people make full use of all available information to make decisions. Thirdly, the expectation that is emphasized by neo-classical macroeconomics is the expectation without systematic prediction of errors, which can be called unbiased expectations, that is, rational expectations. ${ }^{1}$ In terms of the policy, the school believes that if there is a rational expectation, then the government's economic policy is ineffective. According to the inference of relevant policy, it is precisely the rational expectations of the market players and their corresponding behavior adjustment that resolve all the policy intentions of the government to manage the macro economy. On the contrary, the economic macro regulation and management measures of the government in a short-term vision advocated by Keynesianism are ineffective in the overall and long-term. Compared with the short-term economic policies selection based on various opportunities, what the government should do is to formulate long-term policy rules with consistency to reasonably guide people's rational expectations.

The rational expectation has important theoretical enlightenment value, and is even called the sixth revolution in the history of economic development. It has two main contributions. The first is to build modern economics on the basis of information theory, thus making macro and micro economy opened and connected in a specific sense. The second is to introduce the expectation into the economic prediction model and make it measurable and calculable. Both of these are considered to be important advances and achievements in economics. At the practical level, the rational expectations also had a major impact. During the period of more than a few decades, the rational expectation had been regarded as the source of living water in the western countries in pursuit of neo-classical liberal economic thoughts, and supported the popularity of the economic concept of new liberty in the next few decades from the fundamental theoretical logic.

Despite such brilliant achievements, criticism on the rational expectations has always existed. In short, the first is three impossible. One of the prerequisites of rational expectation that people can make reasonable predictions is complete information, which is impossible in real life. The second prerequisite of rational expectation that people can make reasonable predictions is the homogeneous distribution of economic forecasting knowledge, which is also impossible. In addition, the rational expectation is based on the premise of complete market competition and automatic market clearing, and in many cases, this is impossible. Second, at the application level, the rational expectation recognizes the risks but rejects uncertainties, focuses on long-term instead of short-term and advocates government inaction, etc., which actually denies the role of government policy and has little guidance for the optimization of government policies that cannot be avoided in the complicated practical world.

\section{Argumentation on Failure of Rational Expectation: Hypothesis, Path and Mechanism Analysis}

It should be acknowledged that the rational expectation has a certain milestone for the development of economics, and has a major impact on both theory and practices. However, when it is connected with practice and used to guide practice, we can easily find that it is difficult for rational expectations under many assumptions to response sufficiently and verify in real life. Under the circumstances of incomplete competition, inflexible prices and wages and the limitations of information asymmetry, we must make decisions. Thus, a related proposition that needs to be discussed and recognized logically is the failure of rational expectation. In the process of reinterpreting reverse selection, incomplete information and animal spirit, it is not difficult to outline a clear logical clue of failure of rational expectations following the research sequence of George A. Akerlof, Michael Rothschild, Joseph E. Stiglitz, Sanford J. Grossman, and Robert J. Shiller, etc. with relevant thinking on game theory.

\subsection{The Concept of Failure of Rational Expectation}

We believe that it is necessary to clearly put forward and discuss in depth the failure of rational expectations. The so-called failure of rational expectations means that when predicting the future events, due to the effects of incomplete competition, incomplete information and incomplete rationality, the market player cannot make completely accurate expectations and then adjust their actions accordingly, which has a significant correlation and influence on the optimization of government economic management policies. This proposition is mainly based on the following three theoretical assumptions.

First, the assumption of incomplete competition. The assumption of complete competition has great significance

${ }^{1}$ [The United States] Paul Samuelson, William Nordhausen. Economics (The Eighteenth Edition), Posts \& Telecom Press Co., Ltd., 2008, pp. 607-608. 
for us to understand why the market can play a decisive role in the optimization of resource allocation. However, in the human society, even though the market economy has developed to the current state, the real case is still incomplete competition, even for the most developed and mature economy that admires the government inaction the most. Among them, the competition factors can be divided into administrative monopoly factors from the government body and oligopoly factors from the development of the market itself. For different countries and different stages, the formation reasons and combination status of these monopoly factors are different. Although this brings complexity for the analytical framework and analytical methods under the assumption of incomplete competition, we believe that from the original meaning of theories closely related to reality, it is essential for us to research the challenges of complexity, which will make unique cognitive contributions.

Second, the assumption of incomplete information. The incomplete nature of the information in the real world mainly comes from three aspects. First, information collection is costly, and people cannot pay indefinitely, thus it is often difficult to obtain complete information. Second, the people's ability to process information is limited, different and non-homogeneous. It is impossible for everyone to process the relevant information to the same extent. Especially in a broad sense, knowledge, economic theory, and economic model are also kind of information. For market entities, such information is incomplete, and economic knowledge and models can not be evenly distributed among all market entities. The extent to which different individuals master relevant theories and cognitive laws is extremely significant. Third, even economists who have been trained for a long time have to face a vast and unknown world in information processing. In most cases, economists themselves do not know the true economic model and have great controversies over the understanding of the same thing.

Third, the assumption of incomplete rationality. The major crises that have occurred many times in economic history have repeatedly shown that what driving people to take an action is not only rational motivation based on prudent cost-benefit calculation, but also various irrational motives of animal spirits, such as fear, optimism, herd, illusion, etc., which is another type of motivation that drives people to act. In most cases, people are rational, and the results of economic activities are generally predictable, but in the case of a few incidents with significant consequences, both irrationality and rationality influence our actions. Even at specific stages, the irrationality plays a leading role, for example, the social disorder brought by the bubble and the bursting of the bubble, which is represented by the crazy tulip (in the Netherlands hundreds of years ago) and crazy clivia (in China after the reform and opening up).

\subsection{The Mechanism of Failure of the Rational Expectations}

The mechanism of failure of rational expectations can be divided into three levels under the premise of incomplete competition. First, there is some kind of factors triggering failure, which can be called the first factor. Second, after being triggered, the system has two kinds of reactions, one is transmission, the other is interaction, and complex reactions occur between various subjects in the system, which can be called the second stage or intermediate process. Third, for the results, the output of the system after the reaction is significantly magnified and multiplied, which have a significant impact. We will discuss this in detail in the following.

Economic theory has relatively and fully elaborated the impact of incomplete information on the failure of rational expectations. In the 1970s, economics ushered in a revolution around the assumption of loosing complete information. The result was that information economics officially became a branch of economics, which indicated that people have fully accepted the new economic assumption of incomplete information. In addition, incomplete information is also reflected in the economic models used by countries for macroeconomic management. Since Jan Tinbergen created an econometric model for the Dutch economy in 1936 and an economic model containing 48 equations for the United States in 1938, it has been the main tasks for the national macro administrations in various countries to predict the future economic trends with models and adjust policies accordingly. Over the past half century, economic models have become more and more complicated. For example, the econometric model system of the United Nations includes thousands of equations, which are connected to the econometric model of every major country in the world, running day and night to help people obtain information about the global economy. Even so, in 2008, there was a global financial crisis that was not predicted by the model (and, shortly before the crisis, the model gave optimistic predictions). ${ }^{2}$ This shows that even in today's highly developed information technology and knowledge explosion, even well-trained first-class

\footnotetext{
2 "In September 2008... the macroeconomic model suffered a complete failure when we needed it the most. In fact, the government organizations and the private sector, such as the Federal Reserve, the International Monetary Fund, and JP Morgan Chase, etc. all released optimistic economic forecasts." [The United States] Alan Greenspan. The Age of Turbulence, CITIC Publishing House, 2014, p.6.
} 
economists, even with world-class computers and the most complicated economic models, the experts still have many unknown, chaotic and misjudgment for the real world and future scenarios, not to mention thousands of individuals who rely mainly on intuition and experience.

Compared with abundant discussion on incomplete information, there has been almost blank in the discussion on incomplete rationality or irrational factors. It was not until 2000 that the book Irrational Exuberance published by Robert J. Shiller introduced the irrational factors into the economics officially. In the economic sense, the more direct expression of irrationality is animal spirit that is put forward by Keynes the earliest, who only describes the phenomena. Shiller studied the source of the term animal spirit. According to him, the term originated in ancient Greece, and the philosopher George Santayana constructed a philosophical system focusing on the animal belief. He defined the animal belief as a pure, absolute spirit and a cognitive energy that could not be perceived, the nature of which was intuition. But the animal spirit in Shiller's work is of great economic significance: "In modern economics, animal spirit... refers to the elements that lead to economic turmoil and volatility. It is used to describe the relationship between humans and ambiguity or uncertainty." (1) According to Shiller's insights, animal spirits are mainly manifested in five aspects: confidence and its multipliers, fairness, corruption and fraud, currency illusion, and others' success story. Greenspan summarizes the animal spirits that have had a major impact on macroeconomic operations in the following areas: fear and fanaticism, time preference, herd behavior, dependence, interaction, family orientation, competition, values, optimism tendency, the tendency to cherish the loved ones, self-interest and self-esteem, and so on.(2)

The trigger of the first factor is mostly accidental, but it will transfer the distorted information and distorted emotions, etc. between economic individuals in reality like the falling of "dominoes" gradually to backward from 1, 2, $3 \ldots$ to $\mathrm{n}-1, \mathrm{n}$, thus affecting more and more subjects (as shown in Figure 1).

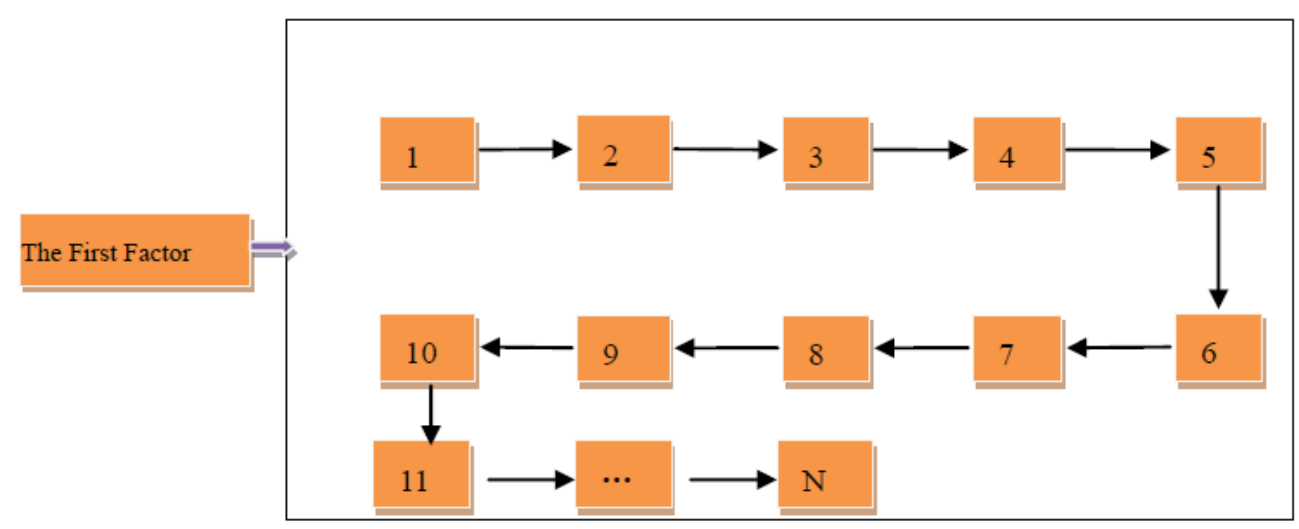

Figure 1. The Transmission after the Accidental Triggering of the First Factor

At the same time of transmission, all the objects are easy to interact with each other, and the whole system is stirred in a complicated and irregular way. Compared with the beginning, the system often presents an unimaginable amplification effect, which is shown in Figure 2.

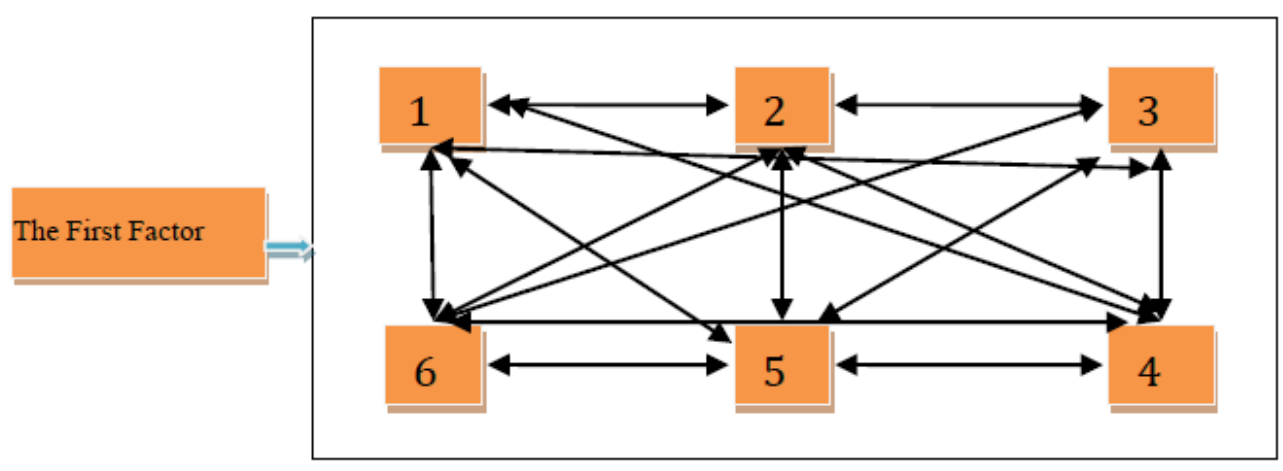

Figure 2. Interaction Between Objects 
The process of failure of rational expectations described above is often seen in other disciplines, such as the herd and the effect of sheep flock in psychology, infectious disease models in epidemiology, and even positive feedback and oscillation circuits in physics. In economics, the principle of multiplier in Keynesian theory can better describe the above. The so-called multiplier refers to the multiple of the change of one variable caused by the change of another variable due to the chain reaction. According to its application in different fields, there are different multipliers, such as investment multiplier, fiscal expenditure multiplier, currency multiplier and foreign trade multiplier, and even incentive multiplier and management multiplier. The failure of the rational expectations and its occurrence and amplification mechanism described in this paper can also be called the irrational expectation multiplier.

It must be pointed out that compared to the investment multiplier, tax multiplier, etc. that can be modeled and relatively and accurately measured, the factors resulting in the failure of rational expectations are mainly certain psychological or emotional state that cannot be measured and calculated in the existing economic analysis or modeled in quantitative. But this does not affect our preliminary summary of what we can do at the observation level, and we must not ignore its existence. How to break the doctrine of immeasurable irrationality that many economists have long believed in, and to incorporate the behaviors that may have a significant impact on the economic system resulted in by various irrational factors into the economic model and quantify will be an important direction in the field of economic quantitative research in the future. As Greenspan pointed out, "repeated observations show that many animal-based behaviors are also predictable and quantifiable... Economics needs to create new economic models that must include human's irrational factors". ${ }^{3}$ However, it is still necessary to make long-term efforts to achieve relatively mature results in this direction.

\section{Investigation on the Phenomenon of Failure of Theoretical Expectation}

\subsection{Lemon Market and Adverse Selection Caused by Incomplete Information}

The so-called lemon market ${ }^{4}$, in fact, is the defective market, also known as Akerlof model market (in 1970, the economist George Akerlof put forward this expression in his paper. The word lemon means defective or useless things in American slang.) Relying on the easy-to-understand second-hand car market, the cognition of the lemon market illustrates the logic that the quality of the goods is not always guaranteed and there are often uncertainties to a large extent. Obviously, the sellers have more information than buyers, and the information between them is asymmetric. These lead to the so-called reverse choice, that is, the goods are decided by the supplier instead of the buyer to be sold or not. Consequently, in the lemon market, there is phenomenon similar to "bad money driving out good money" in Gresham's Law. Thus, the low quality goods flood the market, high quality products are expelled from the market, and finally result in the decline in product quality and the shrinkage in the market. The reverse choice caused by uncertain product quality and asymmetric information between the buyer and the seller can be the first logic observed in the failure of the rational expectations.

\subsection{Incomplete Information Market and Grossman-Stiglitz Paradox}

On the basis of the lemon market, the research on the incomplete information market goes through two stages, which together constitutes the observation aspect of the logic of failure of the rational expectations.

Stiglitz et al. studied the equilibrium problem of competitive markets under incomplete information. There are three classic conclusions: "In the incomplete information market, competitors with complete information may limit the number of products purchased by the consumers, this is not out of intention to establish a monopoly, but only to improve their information status; equilibrium may not exist; competitive equilibrium is not Pareto optimal." It can be seen that in the incomplete information market, even under the assumption of rational expectations, rational people can not first obtain complete information and make rational choices. Secondly, they are influenced by the choices made by rational people with complete information, that is, the static or dynamic games under the incomplete information, thus resulting in greater deviations from rational choices under the assumptions of complete information and rational expectations. Taking China's real estate market in the past 20 years as an example, if the micro-subjects in the market were simply divided into high-risk preference consumers

\footnotetext{
${ }^{3}$ [The United States] Alan Greenspan. The Age of Turbulence, CITIC Publishing House, 2014 edition.

${ }^{4}$ George A. Akerlof. The Market For "Lemons": Quality Uncertainty And The Market Mechanism, Quarterly Journal of Economics, Vol.84, No.3.( Aug., 1970 ), pp. 488-500.

${ }^{5}$ [The United States] Michael Rothschild, Joseph Stiglitz. Equilibrium in Competitive Insurance Markets: An Essay on the Economics of Imperfect Information (1976), Selected Papers of Akerlof, Spence and Stiglitz, The Commercial Press, 2010 Edition, pp. 59-83.
} 
and low-risk preference consumers, then 20 years ago, high-risk preference consumers would invest in real estate while low risk preference consumers would choose to live on their own. Under these two different preferences, there was a game between the behavior of the high risk consumers and that of the low risk consumers, and the preference of the high risk consumers would directly affects the behavior choice of the low risk consumers. For example, if the risk preference value of the high risk seeker is A, and the price of the property determined by A is $\mathrm{P}$, then when A becomes smaller, $\mathrm{P}$ will drop to the price that is more acceptable to the low risk seeker, thus encouraging the low risk taker to buy a house and change their decision of not buying a house because of risk avoidance. Although the high risk seeker and the low risk taker reach their own Nash equilibrium in the game at that time, the Pareto optimality is not achieved. Under the influence of incomplete information, with the rising of real estate prices, there will be huge gap of wealth between the high risk seeker and low risk taker.

Through the introduction of price analysis, the flow of information in the incomplete information market is studied. The study concludes that prices do not fully reflect all available information, especially the information of information owners, and based on this, the Grossman-Stiglitz paradox is proposed. If the equilibrium price fully reveals private information, then because of the motive of free rider, every uninformed person is not willing to pay the cost to become a person with information, let alone the price mechanism of information. This paradox strongly refutes the idea of the efficient market hypothesis that individuals cannot rely on collecting information to obtain excess returns. Since the choice of the information owner will be better than the choice made by the uninformed person, the uninformed person will choose to become the information owner. In this process, rational people can't get complete information first and then make rational choices. Secondly, they are influenced by the choices made by the rational people with complete information, their own rational choice from without information to with information and the impact of the cost of obtaining information on their own behavioral choices.

\subsection{Irrational Behaviors such as Animal Spirit}

Different from the focus of the debate on complete information in the 1970s, after the global financial tsunami triggered by US subprime mortgage crisis in 2008 , the wave of various restoration and development initiated by the economic theory circle also turned their focus to rational assumption, which is represented by Akerlof's animal spirits. In addition to the animal spirit, the effect of sheep flock, the theory of reflexivity and the Paradox of Wang Qin that we have noticed also reveal the irrationality in economic behavior and become another observational aspect of the logic of failure of the rational expectations. The so-called effect of sheep flock ${ }^{6}$ was first part of the research category of animal behavior and psychology, and then included in the research of psychology or management psychology, and later used in microeconomics to analyze the behavioral characteristics of microscopic subjects, also known as the herding effect. It means that microscopic subjects are often influenced by the majority, and follow the public's thoughts or actions, which directly affect the consumer preferences and influence the behavior selection of price preferences in the theory of supply and demand ${ }^{7}$, thus deviating from the rational assumption of microscopic subject. The so-called theory of reflexivity ${ }^{8}$ means that the investors anticipate trends based on market information they have mastered and act accordingly. At the same time, the actions of investors will in turn influence and change the possible trend of the market, and this mutual influence will continue, so that no one can ever grasp the complete information and make a rational choice. Similar to the logic of theory of reflexivity proposed by Soros, Wang Qing proposed the Paradox of Wang Qing ${ }^{9}$ based on a more macro perspective. It is believed that people are more optimistic about the future economic development expectations and form a high degree of consensus. The more they discount the forward income to the current capital market, the more unlikely it is to realize the expectation.

\section{Corrective Path to Failure of the Rational Expectations}

Based on the above analysis, combined with China's practice, in order to achieve the goal of correcting failure of the rational expectations, it is far from enough to rely solely on the demand side of monetary policy and aggregate adjustment. It is necessary to attach importance to rational supply management in China's macroeconomic regulation and control. To implement the policies, it can be considered from the following four aspects.

\footnotetext{
${ }^{6}$ Wilfred Trotter. Instincts of the Herd in Peace and War, 1916.

${ }^{7}$ Hamilton W. D. Geometry for the Selfish Herd, Journal of Theoretical Biology 31 (2), 1971, pp. 295 - 311.

${ }^{8}$ George Soros. The New Paradigm For Financial Markets: The Credit Crisis of 2008 And What It Means, Public Affairs, 2008.

${ }^{9}$ Definition of the "Paradox of Wang Qing”, China Business News, July 29, 2013.
} 
First, implement the concept of scientific development. Rational supply management should first formulate the outline and promote the overall coordination under the guidance of scientific development in the broad coverage. The development pursued by the scientific outlook on development is comprehensive, coordinated and sustainable, emphasizing the holistic and balanced development, focusing on the sustainability of the combination of current development and long-term development. The concepts, the direction of guidance and the goals required by scientific development are in fact more targeted at the structural aspects of the national economy that are uncoordinated, unbalanced, and "one leg is short and the other leg is short", far from being achieved by single regulatory requirement and the total amount of regulation. Therefore, the implementation of the scientific outlook on development will require macroeconomic regulation and control to exert force from the supply side, optimize the structure through rational supply management, promote coordination and balance, and promote scientific development. Overall coordination is an important scientific and ideological method and working method for handling major relationships. It is also the fundamental method for implementing the scientific outlook on development. At the level of economic development, it mainly covers five aspects of urban and rural development, regional development, economic and social development, harmonious development of people and nature, domestic development and opening up to the outside world, as well as the coordination of various interests. To achieve overall coordination, it is particularly necessary to rely on scientific, innovative, and multi-faceted institutional supply under rational supply management. Despite the existence of failure of the rational expectations, the mainstream of economic development and future development trends of an economy are still expected to follow the main line of rationality, but it is necessary to inhibit the irrationality. The essence of correcting and resolving the failure of the rational expectations by China's macroeconomic rational supply management is to promote the structural optimization of Chinese economy in an active and forward-looking way, to create an upgraded version of Chinese economy, and to focus on the improvement of the quality of economic development while focusing on the scale of economic development so as to catch up with and surpass the first comers in the modernization process and realize the Chinese Dream of the people's better life.

Second, adjust the lemon market. In combination with the financing difficulties of Chinese SMEs and the difficulty of employment of college students, we should strengthen the relevant institutional supply. The mitigation measures are as follows. First, it can provide useful independent third-party support for financing evaluation of SMEs based on principal-agent theory, for example, when SMEs use intangible assets such as intellectual property to mortgage or pledge loans, the third-party body can issue a persuasive proof for its financing or guarantee. Secondly, it should make full use of the network platform to strengthen the channels of information exchange and signal transmission on the basis of real and effective, and alleviate the degree of information asymmetry. Thirdly, for the college students blindly labeling themselves to walk out of the lemon range, consideration should be given to incorporate valid information such as student transcripts and social activity records, etc. into the scope of consideration by employers, and optimize the competitive interview system to utilize and optimize the existing human resources. Considering at the level of correction, the following measures should be taken. First, effectively transform government functions to create a sound environment for the branding, growth and chain operation of SMEs, and pay attention to supervising and guiding industry development norms, and establishing a sound licensing system. Second, vigorously promote education reform, adjust the structure of higher education based on market demand, focus on improving the quality of higher education, reduce the number of lemon in the college student labor market, and get rid of the restriction of lemon market.

Third, rationalize the price mechanism. In the incomplete information market, the logical path of competition will be more complicated, the behavioral choice of micro-subjects is more diversified than that under the theory of rational expectations, and the price system, which is used as a means of transmitting information to achieve Pareto optimality of resource allocation, has not been straightened out in many details in practical uncompetitive market, let alone the situation that the price system cannot fully reflect the information. Based on this, we must first focus on rationalizing the price mechanism to allow information to be transmitted smoothly. On this basis, competitive markets under incomplete information often fail to achieve Pareto optimality and have a negative impact on the increasing gap between the rich and the poor as described above. Therefore, the system construction and policy means should focus on clearing signal channels, strengthen the exchange and sharing of information, establish an effective information platform, and minimize the distortion of behavior caused by information asymmetry.

Fourth, hedging the animal spirit. The countermeasures to correct and resolve the irrational behaviors caused by the animal spirit, the effect of sheep flock and the Paradox of Wang Qing, etc. can be summarized into the following eight-word policies at four levels. First, scientific development and overall coordination. Under the 
background of scientific development and overall coordination and the restriction of related mechanisms, the virtual economic speculations generated by confidence and confidence multipliers can be reduced with the optimization and adjustment of the national economic structure. Mechanism fairness and psychological fairness can be improved steadily through interaction and supplement. Reduce the risk brought by the currency illusion, and solve the problem of unsettled mechanism remaining in the process of rapid economic growth. Clearly understand our own stage of economic development and adhere to the economic development strategy of the same line. Second, structure optimization, upgrading and improvement. Although dominated by the animal spirit, the operation of the national economy is first and foremost based on the rational expectations of information response to the macro-economy. In other words, the economic development level and future development trend of an economy are still expected to follow the rational main line, but it should be more proactive, positive and forward-looking to promote the structural optimization of Chinese economy and create an upgraded version of Chinese economy. While focusing on the scale of economic development, we should pay more attention to improving the quality of economic development. Third, institutional supply and mechanism innovation. To correct and resolve the animal spirit, special emphasis should be placed on strengthening institutional supply and promoting institutional innovation, that is, releasing the reform dividends. This can effectively guide the public's confidence and rationalize the confidence multiplier, solve the problem of institutional fairness and psychological fairness to a large extent, especially help straighten out the original mechanism and reduce the loophole type of fraud. By providing real and effective real-time information when necessary, help the public to reduce the irrational factors such as currency illusion to a certain extent. Fourth, the advantage of the latecomer and the strategy of catch-up. Rational supply management should pay special attention to grasping the development strategy of the national economy, and fully recognize the necessity and importance of the relative latecomer catching up with and surpassing the relative forerunner in the modernization stage as well as the basic realization premise of feasibility. Give full play to the late-developing advantages of developing economies, and firmly grasp the center of economic construction all the time. Combine China's ongoing three-step modernization strategy, develop conservatively and unusually, and continue to implement economic catch-up in a firm and pragmatic manner.

\section{References}

Alan, G. (2014). The Age of Turbulence. CITIC Publishing House, 2014 edition.

Definition of the "Paradox of Wang Qing". China Business News. July 29, 2013.

George, A., \& Akerlof. (1970). The Market For "Lemons": Quality Uncertainty and The Market Mechanism. Quarterly Journal of Economics, 84(3), 488-500. https://doi.org/10.2307/1879431

George, S. (2008). The New Paradigm For Financial Markets: The Credit Crisis of 2008 And What It Means. Public Affairs, 2008.

Hamilton, W. D. (1971). Geometry for the Selfish Herd. Journal of Theoretical Biology, 31(2), 295-311. https://doi.org/10.1016/0022-5193(71)90189-5

Michael, R., \& Joseph, S. (1976). Equilibrium in Competitive Insurance Markets: An Essay on the Economics of Imperfect Information (1976). Selected Papers of Akerlof, Spence and Stiglitz, The Commercial Press, 2010 Edition, 59-83. https://doi.org/10.1007/978-94-015-7957-5_18

Paul, S., \& William, N. (2008). Economics (18th ed.). Posts and Telecom Press Co., Ltd., 2008 edition.

Wilfred, T. (1916). Instincts of the Herd in Peace and War, 1916-1919.

\section{Copyrights}

Copyright for this article is retained by the author(s), with first publication rights granted to the journal.

This is an open-access article distributed under the terms and conditions of the Creative Commons Attribution license (http://creativecommons.org/licenses/by/4.0/). 